\title{
Evidence for long-lived polar vortex air in the mid-latitude summer stratosphere from in situ laser diode $\mathrm{CH}_{4}$ and $\mathrm{H}_{2} \mathrm{O}$ measurements
}

\author{
G. Durry ${ }^{1,2}$ and A. Hauchecorne ${ }^{1}$ \\ ${ }^{1}$ IPSL, Service d'Aéronomie, UMR 7620, BP 3, 91371 Verrières-le-Buisson Cédex, France \\ ${ }^{2}$ GSMA, UMR 6089, Université de Reims, BP 1039, 51687 Reims, Cédex 2, France
}

Received: 27 October 2004 - Published in Atmos. Chem. Phys. Discuss.: 9 March 2005

Revised: 9 May 2005 - Accepted: 9 May 2005 - Published: 15 June 2005

\begin{abstract}
A balloon borne diode laser spectrometer was launched in southern France in June 2000 to yield in situ stratospheric $\mathrm{CH}_{4}$ and $\mathrm{H}_{2} \mathrm{O}$ measurements. In the altitude region ranging from $20 \mathrm{~km}$ to $25 \mathrm{~km}$, striking large spatial structures were observed in the vertical concentration profiles of both species. We suggest these patterns are due to the presence of long-lived remnants of the wintertime polar vortex in the mid-latitude summer stratosphere. To support this interpretation, a high resolution advection model for potential vorticity is used to investigate the evolution of the Arctic vortex after its breakdown phase in spring 2000.
\end{abstract}

\section{Introduction}

A better understanding of the transport and mixing of ozone and other chemically-active trace constituents from the wintertime polar vortex into the mid-latitude stratosphere is needed to address the observed decline of mid-latitude ozone (Hauchecorne et al., 2002). Hess and Holton (1985) suggested that remnants of the polar vortex could persist a long time after the spring breakdown as "frozen" in the mean summertime flow. During the Stratospheric Photochemistry, Aerosols, and Dynamics Expedition (SPADE) campaign in late April 1993, the existence of such vortex remnants was confirmed in the spring mid-latitude stratosphere by investigating in situ measurements of $\mathrm{O}_{3}, \mathrm{CH}_{4}, \mathrm{~N}_{2} \mathrm{O}$ and CFCs obtained during several flights of the ER-2 aircraft from Moffett Field, California (Newman et al., 1996). Orsolini (2001) further studied these vortex remnants during the spring and the summer 1998 using a high-resolution stratospheric chemical transport model applied to some selected simple long-lived tracers. He predicted some "fossil" debris of the circumpolar vortex subsisting even in August in the lower stratosphere

Correspondence to: A. Hauchecorne

(alain.hauchecorne@aerov.jussieu.fr) and being slowly advected by the summer easterlies wind regime. He further underlined the need for tracer measurements at summertime to confirm the real existence of these long-lived vortex remnants. The important pending issue is the impact on mid-latitude ozone of potentially chemicallyactive and ozone-depleted polar air subsisting a long time after the spring vortex break-up and being advected to midlatitude where it is likely to finally mix down through smallscale turbulent processes. In this paper, we examine in situ balloonborne methane and water vapor measurements performed at mid-latitudes in late June 2000 that have revealed large and unexpected spatial structures in the lower stratosphere. We think these striking variations in the tracers concentrations could be the signature of "fossil" debris from the Arctic polar vortex, confirming thereby the former predictions of Orsolini (2001). We support our interpretation by using a high-resolution advection model for potential vorticity to investigate the evolving of the circumpolar artic vortex from its spring break up until the time period of the in situ measurements.

\section{In situ observations}

The SDLA ("Spectromètre à Diodes Lasers Accordables") is a balloonborne tunable diode laser spectrometer devoted to the in situ monitoring of $\mathrm{H}_{2} \mathrm{O}$ and $\mathrm{CH}_{4}$ in the lower stratosphere by infrared absorption spectroscopy (Durry and Megie, 1999). With the SDLA, two nearinfrared telecommunication-type laser diodes are connected by means of optical fiber to a two-mirrors multipass optical cell operated open to the atmosphere that provides a $56 \mathrm{~m}$ absorption path length. The laser beams are absorbed in situ by the ambient methane and water vapor molecules as it is bouncing back and forth between both mirrors of the optical cell. In situ absorption spectra of methane in the 1.65-micron region and water vapor in the 1.39-micron

(C) 2005 Author(s). This work is licensed under a Creative Commons License. 


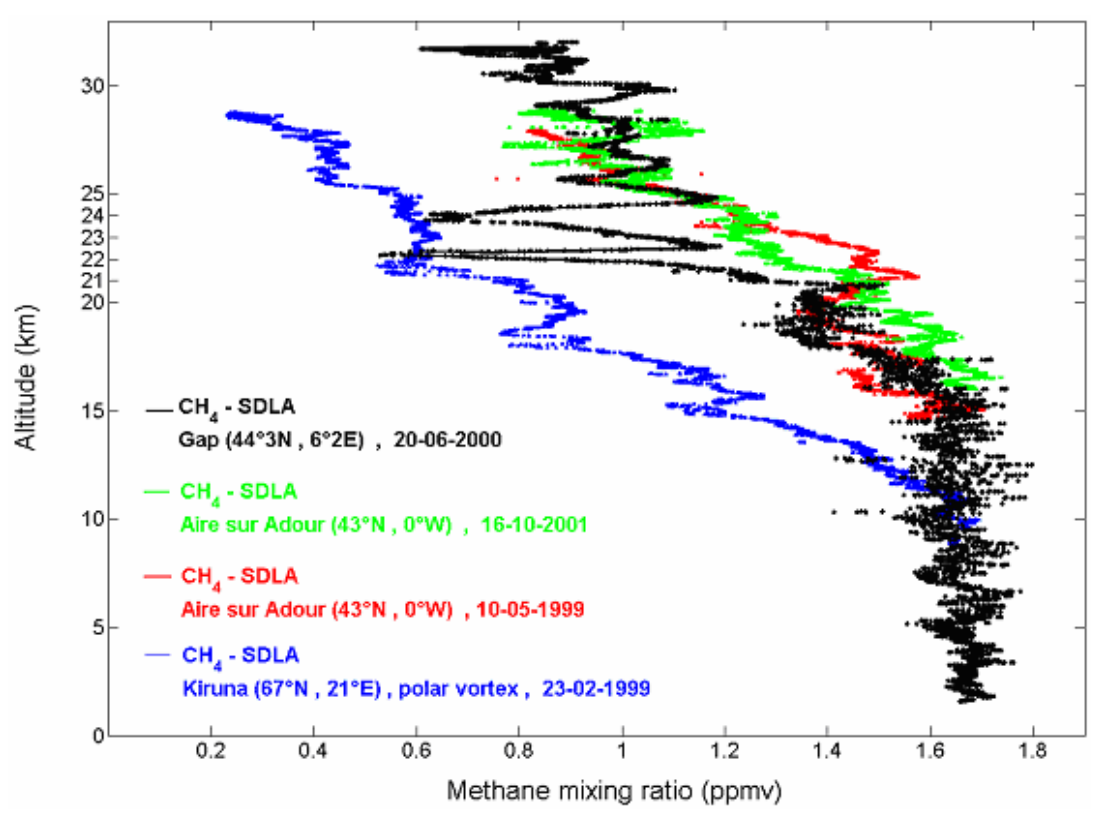

Fig. 1. In situ vertical concentration profiles of $\mathrm{CH}_{4}$ yielded by the SDLA balloonborne laser diode sensor at mid-latitudes in southern France in 1999, 2000 and 2001 (in red, black and green) and in the wintertime Arctic vortex in northern Sweden (in blue) in 1999. A strong decrease in the methane content was observed at mid-latitude in June 2000 between $20 \mathrm{~km}$ and $25 \mathrm{~km}$.

region are recorded simultaneously at 1-s-intervals at the cell output using a differential detection technique (Durry et al., 2000). The Beer Lambert law is then used to relate the absorption of laser energy to the molecular concentration. Practically, the molecular mixing ratio is retrieved from the absorption spectra with a non-linear least-squares fit to the full molecular line shape in conjunction with onboard in situ atmospheric pressure and temperature measurements and by use of an adequate molecular model. The concentration data reported in this paper were obtained by processing the in situ spectra using, respectively, the HITRAN molecular database for $\mathrm{CH}_{4}$ and our revisited spectroscopic parameters for $\mathrm{H}_{2} \mathrm{O}$ (Parvitte et al., 2002). The achieved precision error in the concentration measurements of both species ranges from $5 \%$ to $10 \%$. More details on the used laser probing technique, the concentration retrieval and the various sources of errors are given in (Durry et al., 2002). The SDLA was flown on 20 June 2000 (launching at 21:00 UT), within the framework of the Third European Stratospheric Experiment (THESEO-2000) from Gap in southern France $\left(44^{\circ} \mathrm{N}, 6^{\circ} \mathrm{E}\right)$. The achieved methane vertical profile is reported in Fig. 1. It is made of a few thousands of concentration points obtained in situ at 1-s-intervals during the ascent of the gondola in the middle atmosphere. Two large and unexpected spatial structures are observed in the $20-\mathrm{km}$-to-25-km altitude region indicating a sudden decrease in the methane content of approximately 0.8 ppmv. The same phenomenon is featured in the methane profile yielded by the SDLA during its slow descent in the lower stratosphere, reducing thereby the likeliness of some instrumental artifact. To compare with previous $\mathrm{CH}_{4}$ measurements at mid-latitudes, the data yielded by the SDLA in May 1999 (THESEO) and October 2001 (validation of the ODIN satellite) from Aire-sur-Adour $\left(43^{\circ} \mathrm{N}\right)$ in southern France are added in Fig. 1. The stratospheric methane concentration reaches a minimum near $0.5 \mathrm{ppmv}$ at $22 \mathrm{~km}$ for the flight in June 2000. This value can be further compared to the methane measurements yielded by the SDLA in February 1999 in the polar Arctic vortex as the sensor was flown from Kiruna $\left(67^{\circ} \mathrm{N}\right)$ in northern Sweden (THESEO). The matching between the methane concentration values yielded by the SDLA in the polar Arctic vortex in 1999 and in the midlatitude summer stratosphere in 2000 was an impetus for us to further investigate the possible presence of polar air remnants from the 2000-Arctic vortex at the time and place of the SDLA flight in Gap. The $\mathrm{H}_{2} \mathrm{O}$ profile yielded by the SDLA during the slow descent of the gondola in the lower stratosphere is shown in Fig. 2. The water vapor profile features both spatial structures in the same altitude region, with a sudden striking increase in the water vapor concentration of more than one ppmv. With the molecular hydrogen not taken into account, the total hydrogen budget $\left[\mathrm{H}_{2} \mathrm{O}\right]+2\left[\mathrm{CH}_{4}\right]$ is found at approximately $6.9 \mathrm{ppmv} \pm 0.1 \mathrm{ppmv}$ in the altitude region where the structures occur. This value seems in good agreement with former balloonborne measurements of the hydrogen budget in the Arctic Vortex (Engel et al., 1996; Zöger et al., 1999). The anti-correlation found between methane and water vapor is further an indication that the increase in the $\mathrm{H}_{2} \mathrm{O}$ content is not an artifact due to water vapor outgassing from the balloon envelope or from the spectrometer itself (Durry and Megie, 1999). 


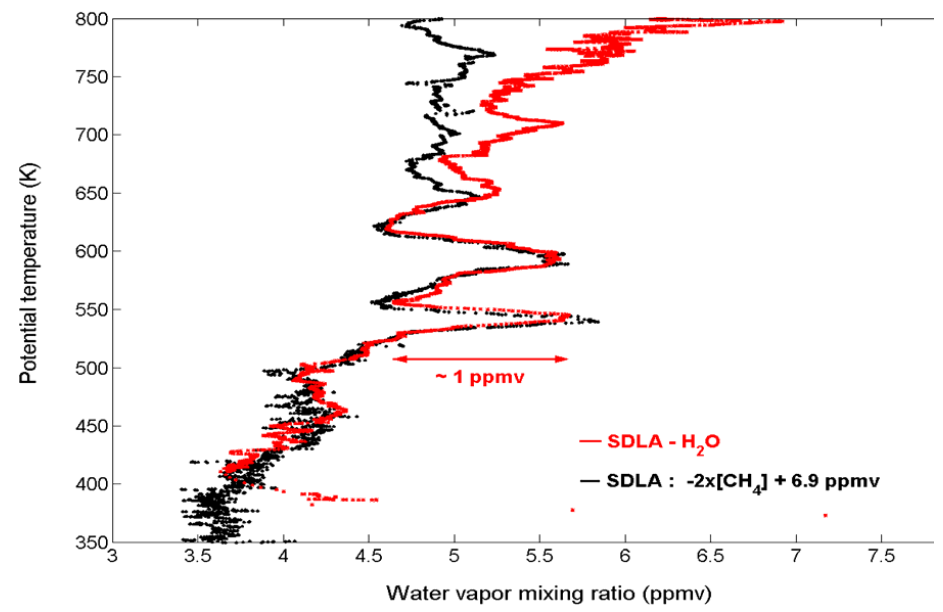

Fig. 2. The $\mathrm{H}_{2} \mathrm{O}$ vertical profile yielded by the SDLA during the flight from Gap on 20 June 2000. The water vapor data were obtained during the slow descent of the instrument in the lower stratosphere at nighttime. The corresponding methane measurements of the SDLA (Fig. 1) were scaled to $-2 \times\left[\mathrm{CH}_{4}\right]+6.9 \mathrm{ppmv}$ and added to the figure.
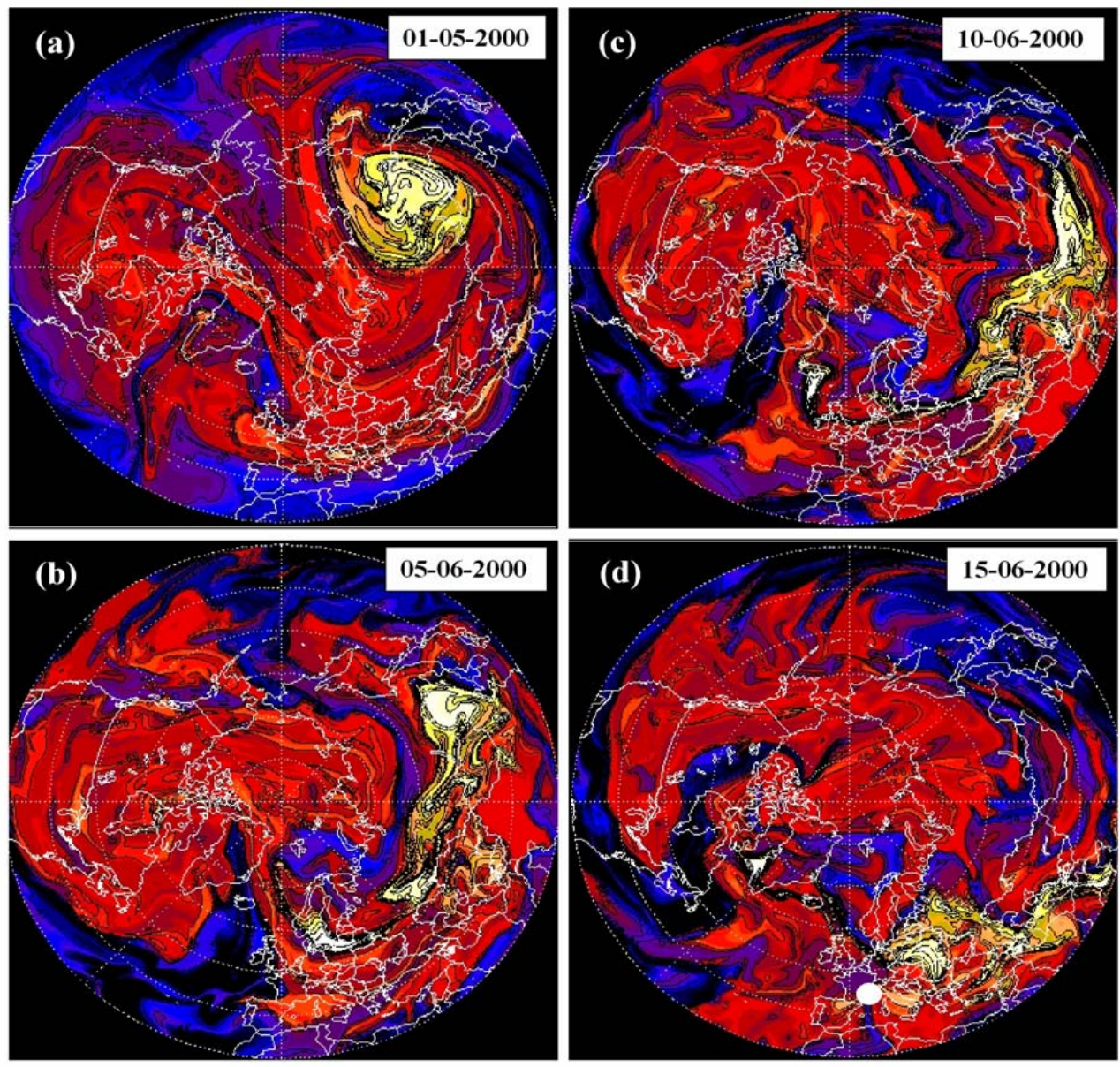

Fig. 3. Results from a $590 \mathrm{~K}$ high resolution advection integration obtained with the MIMOSA model. Contours are of potential vorticity $\left(10^{-8} \mathrm{~K} \mathrm{~m}^{2} \mathrm{~s}^{-1} \mathrm{~kg}^{-1}\right)$. (a)-(b) In May 2000, a remnant of the wintertime vortex is observed over northern Asia. (c)-(d) In June, the vortex is propagated westwards in the summer easterlies regime. The location of the SDLA flight at mid-latitudes is marked with a white circle in (d). 


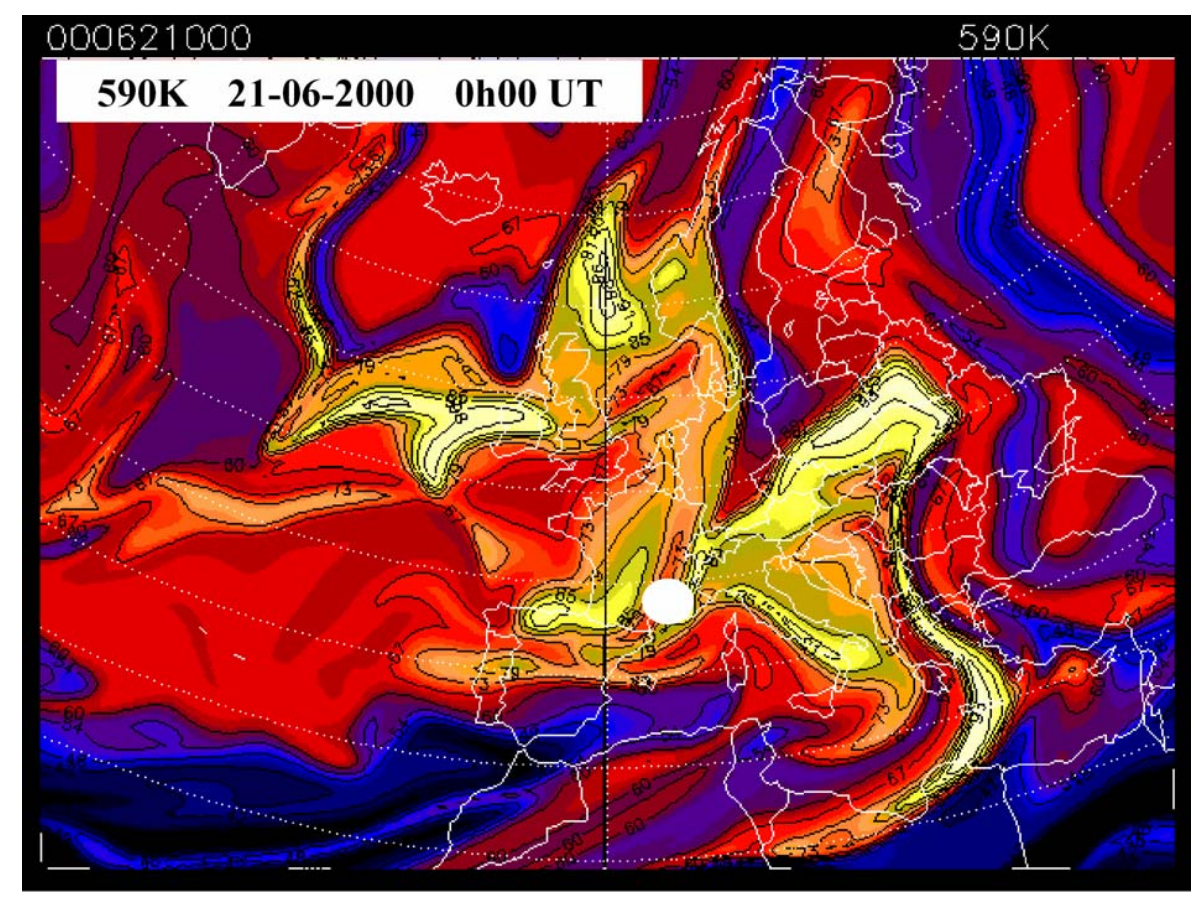

Fig. 4. Expanded view on the PV distribution at $590 \mathrm{~K}$ from the MIMOSA model on 20 June 2000 at midnight. Units are in Fig. 3 . High-PV polar air is predicted in the region of the flight that is marked with a white circle.

\section{Interpretation and conclusion}

To understand the significance of the observed patterns in the $\mathrm{CH}_{4}$ and $\mathrm{H}_{2} \mathrm{O}$ measurements, we use the simulated potential vorticity distribution on several isentropic levels obtained during the period from May to June 2000 with the "Modele Isentropique de transport Mesoechelle de l'Ozone Stratosphérique par Advection" (MIMOSA), a highresolution advection model for potential vorticity (PV). The MIMOSA model performs high resolution advection calculations based on the ECMWF wind field to provide PV fields on isentropic surfaces (Hauchecorne et al., 2002). The model is run independently on each isentropic surface; this technique to reconstruct high-resolution tracer profiles by carrying separate isentropic simulations was initiated by Orsolini (1995) and Newman et al. (1996). Basically, the model advects $\mathrm{PV}$ on isentropic levels by the horizontal wind components on a $x-y$ grid centred at the North Pole with a resolution of 6 points per degree. The model is run on 26 isentropic levels from 450 to $700 \mathrm{~K}$ with a $5 \mathrm{~K}$ interval. It allows reconstructing PV-anomaly layers as thin as $10 \mathrm{~K}$ even if ECMWF fields used for the advection have a coarser vertical resolution (about $25 \mathrm{~K}$ ). To preserve the homogeneity of the field, a regridding of the PV field on the original grid is made every $6 \mathrm{~h}$. The diabatic evolution of the PV field at large scales can be extracted from ECMWF fields. In MIMOSA this is made by applying a relaxation toward the ECMWF PV field with a time constant of 10 days. Using this procedure, it is possible to run continuously the model during long periods and to follow the evolution of polar and tropical intrusions at mid-latitudes (Heese et al., 2001). However, the application of a relaxation term prevents to follow the evolution of a given structure for a period longer than 15 to 20 days. In order to follow the advection of vortex remnants until midJune, 1.5 month after the final winter vortex break-down in early May, MIMOSA was run in a special mode in which the relaxation term is suppressed. This can be done in MayJune because the easterly summertime circulation is almost perfectly zonal and there is very little deformation of air masses. However, the expected uncertainty on the location of advected structures is increasing with time. (Hauchecorne et al., 2002; Heese et al., 2001). Basically, the uncertainty in predicting the location of the advected structures is approximately one degree for a simulation run over a ten-day period of time. The advection calculation was initialised with the 590 K ECMWF PV contours on 1 May and with the $590 \mathrm{~K}$ daily winds extracted from ECMWF analyses at 00:00 UT. The results are presented on Fig. 3. A stratospheric warming occurred at the end of March and the polar vortex splitted in 2 parts. A well-defined vortex structure originated from one of the 2 parts is observed over northern Asia on 1 May (Fig. 3a). In May, the vortex slowly deforms and filamentary structures appear as well as some debris resulting from some splitting of the vortex, which are further mixed down. Nevertheless, some coherence of the core of the vortex is maintained (Fig. 3b). In June, the vortex starts to propagate 


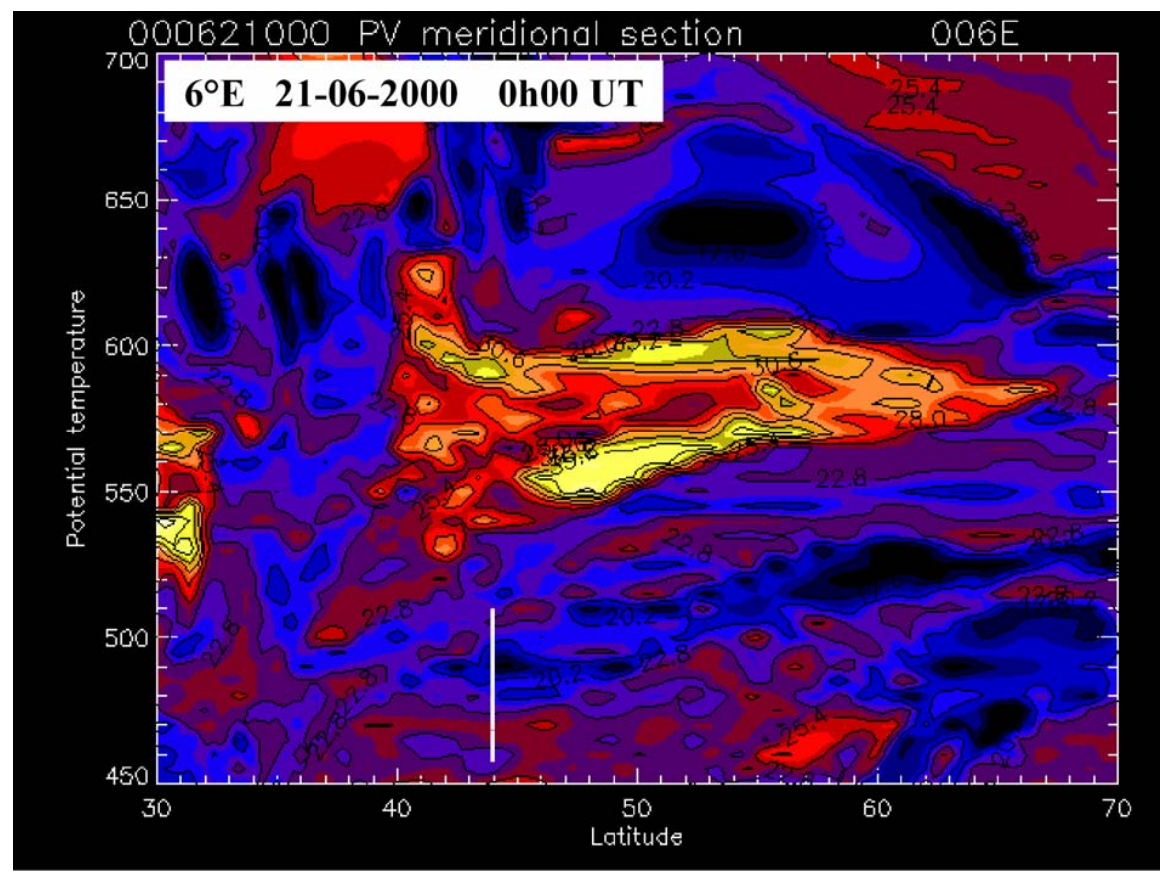

Fig. 5. Meridional section of the PV distribution with potential temperature on 20 June 2000 at midnight yielded by the MIMOSA model. Units are in Fig. 3. The latitude of SDLA flight is indicated by white vertical bar. Two regions of high-PV polar air around $600 \mathrm{~K}$ and $550 \mathrm{~K}$ are observed at the latitude of the flight. Near $600 \mathrm{~K}$ and $550 \mathrm{~K}$, two large spatial structures were observed in the $\mathrm{CH}_{4}$ and $\mathrm{H}_{2} \mathrm{O}$ measurements (Fig. 2).

westwards in the summer easterlies regime. It is deformed in a ribbon-like shape (Fig. 3c) but a certain coherence is still maintained which is likely due to the weak meridional shears characterizing the easterlies regime (Hess and Holton, 1985). Finally, the polar air masses arrive over southern France in the mid-June period (Fig. 3d). The day of the SDLA-flight, high-PV polar air masses are predicted over the Gap region as illustrated in Fig. 4. A meridional section of the PV distribution with potential temperature is shown in Fig. 5 for the day of the SDLA-flight, featuring two regions of high$\mathrm{PV}$ polar air around $600 \mathrm{~K}$ and $550 \mathrm{~K}$. The error in the location of the advected structures is of two-to-three degrees for a MIMOSA simulation run over a one-month period of time: in Fig. 5, both structures at $600 \mathrm{~K}$ and $550 \mathrm{~K}$ are predicted near latitude of $47^{\circ} \mathrm{N}$ instead of $44^{\circ} \mathrm{N}$ (Gap). It is nevertheless in agreement with the expected uncertainty of MIMOSA.This analysis gives a hint to the presence of polar air masses causing the two large spatial structures observed in the SDLA methane and water vapour concentration profiles. Furthermore, the structures are detected by SDLA and predicted by MIMOSA at altitudes above $20 \mathrm{~km}$, i.e. in the midstratosphere. It is consistent with previous observations from Orsolini (1998) who found a different behaviour in the tracers between the lower and the mid-stratosphere. In the lower stratosphere, i.e. at altitudes below $20 \mathrm{~km}$, the vortex remnants are rapidly mixed through the action of synoptic-scale eddies penetrating into the stratosphere and are meridionally bounded by the sub-tropical jet (Konopka et al., 2003). Simulations with MIMOSA in the lower stratosphere, at $450 \mathrm{~K}$ and below (not shown), present little evidence for long-lived remnants which probably indicates more rapid mixing in this region of the atmosphere.

To conclude, there are several lines of evidences from the balloon measurements (low $\mathrm{CH}_{4}$ concentration values, hydrogen budget) and from the modelling (advection calculations, intrusion of high-PV polar air) to support the hypothesis of polar vortex debris subsisting in the mid-latitudes summer stratosphere until end of June. An important pending issue consists of investigating the ozone chemistry inside these vortex remnants and trying to better understand the turbulent mixing and transport processes that will finally mix down the remaining polar air masses with mid-latitudes air. Some aspects of the ozone chemistry inside the vortex remnants have been investigated by Konopka et al. (2003) using the Chemical Lagrangian Model of the Stratosphere (CLaMS). For our part, we intend to further address this issue using the high resolution $\left(1^{\circ} \times 1^{\circ}\right)$ chemistry-transport model MIMOSA-CHIM (Marchand et al., 2003). This model couples the high-resolution advection model MIMOSA with a radiation scheme and with the full stratospheric chemistry package of Reprobus (Lefèvre et al., 1998) and was used to to study the dynamical and chemical evolution of polar filaments during winter 1999/2000. 
Acknowledgements. The authors are deeply grateful to G. Megie for his help in setting up the SDLA project. The Technical Department of the Institut National des Sciences de l'Univers (INSU-CNRS) is thanked for its assistance in the balloon operations. The work described in this paper was supported by the CNRS, the CNES, the European Commission and the French Program for Atmospheric Chemistry.

Edited by: G. Vaughan

\section{References}

Durry, G. and Mégie, G.: Atmospheric $\mathrm{CH}_{4}$ and $\mathrm{H}_{2} \mathrm{O}$ monitoring with near-infrared InGaAs laser diodes by the SDLA, a balloonborne spectrometer for tropospheric and stratospheric in situ measurements, Appl. Opt., 38, 7342-7354, 1999.

Durry, G., Pouchet, I., Amarouche, N., Danguy, T., and Mégie, G.: Shot-noise-limited dual-beam detector for atmospheric trace-gas monitoring with near-infrared diode lasers, Appl. Opt., 39, 56095619, 2000.

Durry, G., Hauchecorne, A., Ovarlez, J., Ovarlez, H., Pouchet, I., Zeninari, V., and Parvitte, B.: In situ measurement of $\mathrm{H}_{2} \mathrm{O}$ and $\mathrm{CH}_{4}$ with telecommunication laser diodes in the lower stratosphere: dehydration and indication of a tropical air intrusion at mid-latitudes, J. Atmos. Chem., 43, 175-194, 2002.

Engel, A., Schiller, C., Schmidt, U., Borchers, R., Ovarlez, H., and Ovarlez, J.: The total hydrogen budget in the Arctic winter stratosphere during the European Arctic stratospheric ozone experiment, J. Geophys. Res., 101, 14 495-14 503, 1996.

Hauchecorne, A., Godin, S., Marchand, M., Heese, B., and Souprayen, C.: Quantification of the Transport of Chemical Constituents from the Polar Vortex to Middle Latitudes in the Lower Stratosphere using the High-Resolution Advection Model MIMOSA and Effective Diffusivity, J. Geophys. Res., 107, 82898302, 2002.
Heese, B., Godin, S., and Hauchecorne, A.: Forecast and simulation of stratospheric ozone filaments: A validation of a highresolution potential vorticity advection model by airborne ozone lidar measurements in winter 1998/1999, J. Geophys. Res., 106, 20011-20 024, 2001.

Hess, P. G. and Holton, J. R.: The origin of temporal variance in long-lived trace constituents in the summer stratosphere, J. Atmos. Sci., 42, 1455-1463, 1985.

Konopka, P., Grooss, J. U., Bausch, S., Muller, R., McKenna, D. S., Morgenstern, O., and Orsolini, Y.: Dynamics and chemistry of vortex remnants in late Arctic spring 1997 and 2000: Simulation with the Chemical Lagrangian Model of the Stratosphere (CLaMS), Atmos. Chem. Phys., 3, 839-849, 2003,

SRef-ID: 1680-7324/acp/2003-3-839.

Lefèvre, F., Figarol, F., Carlslaw, K. S., and Peter, T.: The 1997 Arctic ozone depletion quantified from three-dimensional model simulations, Geophys. Res. Lett., 25, 2425-2428, 1998.

Marchand, M., Godin, S., Hauchecorne, A., Lefèvre, F., Bekki, S., and Chipperfield, M.: Influence of polar ozone loss on northern midlatitude regions estimated by a high-resolution chemistry transport model during winter 1999/2000, J. Geophys. Res., 108(D5), 8326, doi:10.1029/2001JD000906, 2003.

Newman, P., Lait, L. R., Schoeberl, M. R., et al.: Measurements of polar vortex air in the midlatitudes, J. Geophys. Res., 101 (D8), 12 879-12 891, 1996.

Orsolini, Y.: On the formation of ozone laminae at the edge of the Arctic polar vortex, Quarterly Journal of the Royal Meteorological Society, vol. 121, no. 528, 1923-1941, 1995.

Orsolini, Y.: Long-lived tracer patterns in the summer polar stratosphere, Geophys. Res. Lett., 28, 3855-3858, 2001.

Parvitte, B., Zeninari, V., Pouchet, I., and Durry, G.: Diode laser spectroscopy of $\mathrm{H}_{2} \mathrm{O}$ in the $7165-7185 \mathrm{~cm}^{-1}$ range for atmospheric applications, J. Quant. Spectros. Radiat. Transfer, 75, 493-507, 2002.

Zöger, M., Engel, A., McKenna, D. S., Schiller, C., Schmidt, U., and Woyke, T.: Balloonborne in situ measurements of stratospheric $\mathrm{H}_{2} \mathrm{O}, \mathrm{CH}_{4}$ and $\mathrm{H}_{2}$ at midlatitudes, J. Geophys. Res., 104, 1817-1825, 1999. 